\title{
Thermodynamics and Kinetics of Direct Synthesis of Solar Grade Silicon from Metallurgical Silicon Wafer by Liquid Phase Migration in Solid Silicon
}

\author{
Sakiko Kawanishi ${ }^{1{ }^{*} 1}$, Kunitoshi Matsunaga ${ }^{1, * 2}$, Takeshi Yoshikawa ${ }^{1}$ and Kazuki Morita ${ }^{2}$ \\ ${ }^{1}$ Institute of Industrial Science, The University of Tokyo, Tokyo 153-8505, Japan \\ ${ }^{2}$ Department of Materials Engineering, The University of Tokyo, Tokyo 113-8656, Japan
}

\begin{abstract}
We propose a process for the direct synthesis of solar grade Si from a metallurgical Si wafer focusing on the fact that its microstructure is composed of almost pure Si grains and grain boundaries enriched with impurities. Principally, heating a metallurgical grade Si wafer above its eutectic temperature and applying a temperature gradient allows the grain boundaries to be melted and causes them to migrate to the high-temperature direction. The liquid phases are finally terminated at the end surface, resulting in the upgrading of the Si and making it more favorable for solar cells. In the present paper, to determine the purification effect during the liquid phase migration process, thermodynamic assessment was performed using CALPHAD method. Liquid phase migration experiments were also conducted using synthetic MG-Si (Si-Fe alloy) to determine the reaction time for the process. A maximum migration velocity of $8.17 \times 10^{-7} \mathrm{~m} / \mathrm{s}$ was obtained at $1623 \mathrm{~K}$, which allows the migration process to be accomplished within $3 \mathrm{~min}$ for a $150-\mu \mathrm{m}$ wafer. [doi:10.2320/matertrans.M2017202]
\end{abstract}

(Received July 6, 2017; Accepted August 9, 2017; Published September 25, 2017)

Keywords: silicon, solvent refining, temperature-gradient zone melting, diffusion coefficient

\section{Introduction}

Solar energy is one of the most prominent renewable energies for the upcoming sustainable society because of its environmental cleanliness. However, the cost of installing solar cell systems is still high despite the significant increase in solar cell production during the past decade. To develop a roadmap for grid parity and the widespread use of photovoltaics, an abundant feedstock of low-cost solar grade Si (SOG-Si) is an inevitable requirement. To solve the problems of the conventional Siemens method ${ }^{1,2)}$, that is, its feed rate limitations as well as high production cost, alternative approaches such as the modified Siemens process ${ }^{3)}$ and fluidized bed reactor process ${ }^{4}$ have been proposed. However, the large amount of energy required to convert Si into gaseous phases sets a limit on their cost reduction. Subsequently, metallurgical purification methods such as directional solidification ${ }^{5}$, vacuum refining ${ }^{6)}$, plasma oxidation $^{7-9)}$, and solvent refining ${ }^{10-12)}$ were researched and partly industrialized. Thus, a number of alternative routes have been developed for producing SOG-Si. However, all of the above-mentioned methods require a plurality of processes from upper to lower processes such as ingot casting and wafer slicing, both of which decrease productivity and cost efficiency. Achieving combined direct wafer fabrication and purification will greatly innovate $\mathrm{Si}$ solar cell production.

Metallurgical grade Si (MG-Si), which is produced by the carbothermic reduction of quartz followed by casting of the melt, generally includes $1.5-2 \%$ of impurities such as Al, B, $\mathrm{P}$, and Fe. Typical impurity contents for MG-Si are shown in Table 1. For solar cell applications, the impurity levels are said to be reduced below $0.01 \mathrm{ppmw}$ for transition metals and below 0.3 ppmw for dopant elements. In MG-Si, most

\footnotetext{
${ }^{* 1}$ Corresponding author, E-mail: s-kawa@tohoku.ac.jp. Present address: Institute of Multidisciplinary Research for Advanced Materials, Tohoku University, Sendai 980-8577, Japan

${ }^{*}$ Graduate Student, The University of Tokyo. Present address: Kashima Works, Nippon Steel \& Sumitomo Metal Corporation, Kashima 314 0014, Japan
}

of the metallic impurities are distributed at the grain boundaries mainly as silicide phases, while the $\mathrm{Si}$ grains are almost pure. The low transition metal impurity concentrations of generally less than $1 \mathrm{ppmw}$ in $\mathrm{Si}$ grains are attributed to their extremely small segregation coefficients (e.g., $k_{\mathrm{Fe}}=$ $\left.6.4 \times 10^{-6}, k_{\mathrm{Ti}}=2.0 \times 10^{-613)}\right)$. This spontaneous segregation of impurities enables the remarkable purification of MG-Si if the impurity phases are selectively removed.

In this paper, the authors focus on heat treatment above the eutectic temperature but below the melting point of $\mathrm{Si}$ $(1687 \mathrm{~K})$ with a temperature gradient as schematically shown in Fig. 1. Such a temperature allows the phases enriched with impurities to be melted while the rest of $\mathrm{Si}$ grains remain in a solid state. Additionally, the temperature gradient leads to the migration of the liquid phases towards the higher temperature side of the MG-Si, and eventual termination at the end surface. Purification of the MG-Si can thus be accomplished just by removing the impurity enriched phases accumulated at the surface after the migration. Subsequently, we targeted the development of a process for the direct synthesis of solar cell Si wafer from MG-Si using this migration of the impurity enriched liquid phases combined with the edge-defined film-fed growth process, which has been adopted for the production of ribbon $\mathrm{Si}^{14}$ ) (generally pulled up from a high purity Si bath). The proposed process is schematically shown in Fig. 2. The ribbon $\mathrm{Si}$ is directly pulled up from the MG-Si melt bath, and simultaneous heat treatment of the ribbon $\mathrm{Si}$ from one side enables the impurities to be terminated at the surface during the pulling. To assess the feasibility of the new direct process, the purification limit of MG-Si must be revealed. Additionally, understanding the kinetics of the migration is important for controlling the process.

Therefore, the upgrading of Si by liquid phase migration in solid Si was investigated using both thermodynamic and experimental approaches. The purification limit of the MG-Si with the heat treatment was first evaluated from the equilibrium phase relation using the available thermodynamic data. Secondly, the migration behavior of the liquid 
Table 1 Typical impurity contents in MG-Si and initial impurity contents in simulated MG-Si for the thermodynamic calculations (ppmw).

\begin{tabular}{|c|c|c|c|c|c|c|c|c|c|c|}
\hline & $\mathrm{Al}$ & $\mathrm{B}$ & $\mathrm{C}$ & $\mathrm{Ca}$ & $\mathrm{Cr}$ & $\mathrm{Fe}$ & $\mathrm{Mg}$ & Mn & $\mathrm{P}$ & $\mathrm{Ti}$ \\
\hline Typical impurity contents in MG-Si & $1000-4000$ & $10-50$ & $1000-3000$ & $200-2000$ & $30-300$ & $1000-5000$ & $100-400$ & $100-400$ & $20-50$ & $30-300$ \\
\hline Impurity contents in simulated MG-Si & 1000 & 30 & 2000 & 700 & 200 & 3000 & 200 & 200 & - & 200 \\
\hline
\end{tabular}

(a)

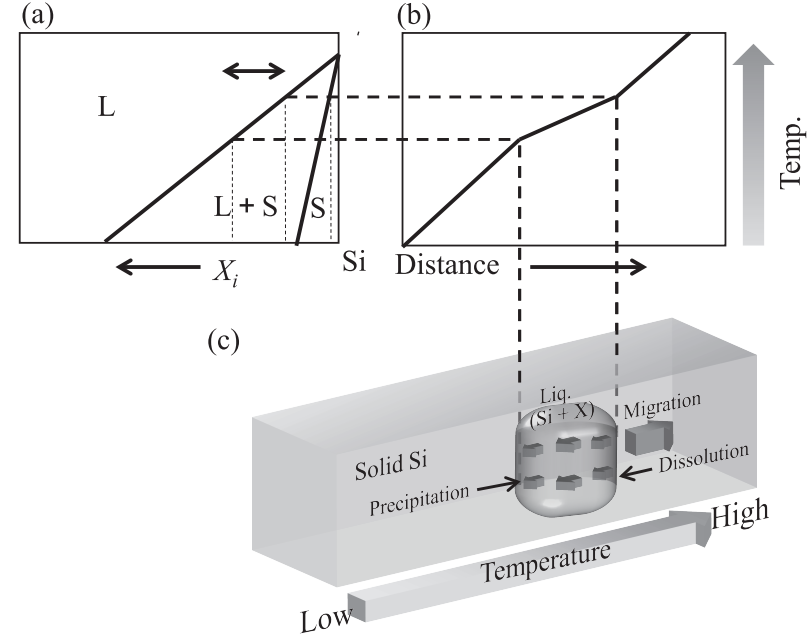

Fig. 1 Schematic representation of heat treatment above the eutectic temperature and below the melting point of $\mathrm{Si}$ with a temperature gradient (a) Partial phase diagram, (b) corresponding temperature distribution, and (c) migration of the liquid phase.

phases dispersed in the solid $\mathrm{Si}$ was investigated. One of the major impurities in MG-Si, Fe, was selected as the sole impurity to simplify the system to enable the kinetics of migration to be more easily assessed. The migration of Fe-Si melt in solid Si at 1523-1623 K was evaluated based on the diffusion in the liquid phase. The interdiffusion coefficient in the liquid phase was evaluated from the measured migration velocity, with the modification of the density difference between the solid and liquid Si.

\section{Thermodynamic Evaluation of Purification Limit}

\subsection{Estimation method}

In this section, the thermodynamic limitations for the purification of MG-Si by the liquid phase migration process are estimated. Here, we assume a condition in which the impurity enriched liquid phase is completely separated from the solid $\mathrm{Si}$ after migration and is isothermally equilibrated with the solid $\mathrm{Si}$ by considering a small temperature difference in the system. $\mathrm{Al}, \mathrm{B}, \mathrm{C}, \mathrm{Ca}, \mathrm{Cr}, \mathrm{Fe}, \mathrm{Mg}, \mathrm{Mn}$, and $\mathrm{Ti}$ were considered as impurities in the MG-Si for the calculations. The composition of the simulated sample of MG-Si used for the thermodynamic estimations is listed in Table 1. Equilibrium phase calculations were conducted to determine the compositions of the solid Si and separated liquid phase.

To obtain the Gibbs energy of the solid Si containing impurity elements, the activity coefficients of the impurity elements in infinitely dilute solution, listed in Table $2^{15-19)}$, were employed. The Gibbs energy of the liquid phase was treated as that of a Redlich-Kister type sub-regular solution $^{20-51)}$. The binary interactions were taken into account when either of the interacting elements was more than $3.5 \mathrm{~mol} \%$ in the liquid phase. Their sub-regular solution pa-

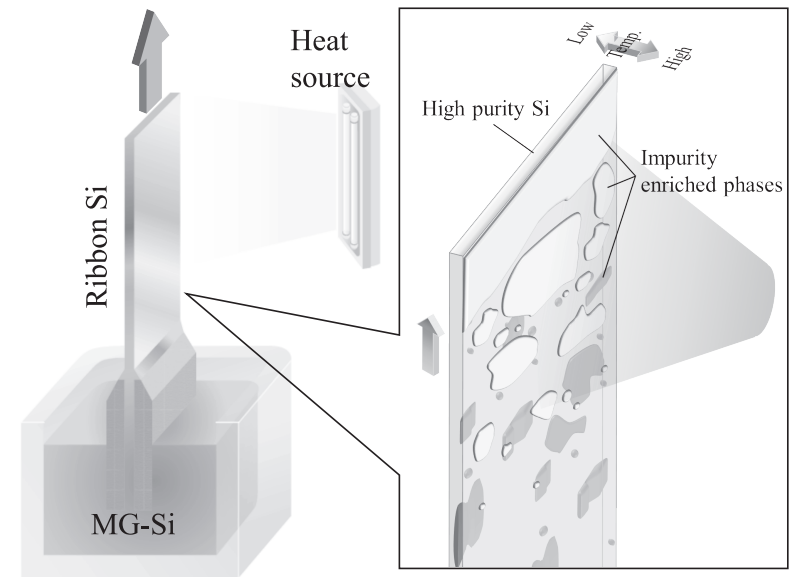

Fig. 2 Schematic diagram of direct synthesis of SOG-Si wafer from MG-Si bath based on migration of the impurity enriched liquid phase.

Table 2 Excess partial molar Gibbs energy of impurities in solid Si.

\begin{tabular}{llll}
\hline Element & Standard state & $R T \ln \gamma_{i}^{s,} / \mathrm{J} \cdot \mathrm{mol}^{-1}$ & Reference \\
\hline $\mathrm{Al}$ & FCC & $93200-14.5 T$ & $15)$ \\
\hline $\mathrm{B}$ & Rhombohedral & $117000-47.6 T$ & $16)$ \\
\hline $\mathrm{C}$ & Diamond & $117000-9.25 T$ & $17)$ \\
\hline $\mathrm{Ca}$ & FCC & $140000-72.6 T$ & $18)$ \\
\hline $\mathrm{Cr}$ & $\mathrm{BCC}$ & $163000-18.6 T$ & $17)$ \\
\hline $\mathrm{Cu}$ & FCC & $166000-47.6 T$ & $19)$ \\
\hline $\mathrm{Fe}$ & $\mathrm{BCC}$ & $198000-54.6 T$ & $17)$ \\
\hline $\mathrm{Mg}$ & $\mathrm{HCP}$ & $193000-69.8 T$ & $18)$ \\
\hline $\mathrm{Mn}$ & $\mathrm{BCC}$ & $217000-66.9 T$ & $17)$ \\
\hline $\mathrm{Ti}$ & $\mathrm{HCP}$ & $133000-41.2 T$ & $17)$ \\
\hline
\end{tabular}

rameters are listed in Table 3. Interactions in the liquid phase between dilute components, that is, interactions between B-C, B-Ca, B-Cr, B-Mg, B-Mn, B-Ti, C-Ca, C-Cr, C-Mg, C-Mn, C-Ti, Ca-Cr, Ca-Mg, Ca-Mn, Ca-Ti, Cr-Mg, Cr-Mn, $\mathrm{Cr}-\mathrm{Ti}, \mathrm{Mg}-\mathrm{Mn}, \mathrm{Mg}-\mathrm{Ti}, \mathrm{Mn}-\mathrm{Ti}$ were not included in the calculation because of their lesser effect on the equilibrium state. Higher order interactions were also ignored. Additionally, the formation of stable compound $\mathrm{SiC}$ was considered using its reliable thermodynamic data ${ }^{52)}$. The equilibrium phase calculation was performed at 1480 $1687 \mathrm{~K}$ using the thermodynamic calculation software FactSage 6.4. The bottom temperature of the estimation was decided from the eutectic temperature of the Fe-Si system to ensure the formation of a liquid phase because $\mathrm{Fe}$ is one of the major impurities in MG-Si.

To enhance the purification, the addition of another element to MG-Si was also studied by changing the composition of the liquid phase during the migration process. Here, $\mathrm{Cu}$ was selected as the additive element owing to its moderate allowable content in solar cell applications $\left(1.5 \mathrm{ppmw}^{53)}\right)$ as well as its good affinity for $\mathrm{Al}, \mathrm{Ca}$, and $\mathrm{Mg}$ in the liquid 
Table 3 Sub-regular solution parameters of the liquid phase used for the calculation.

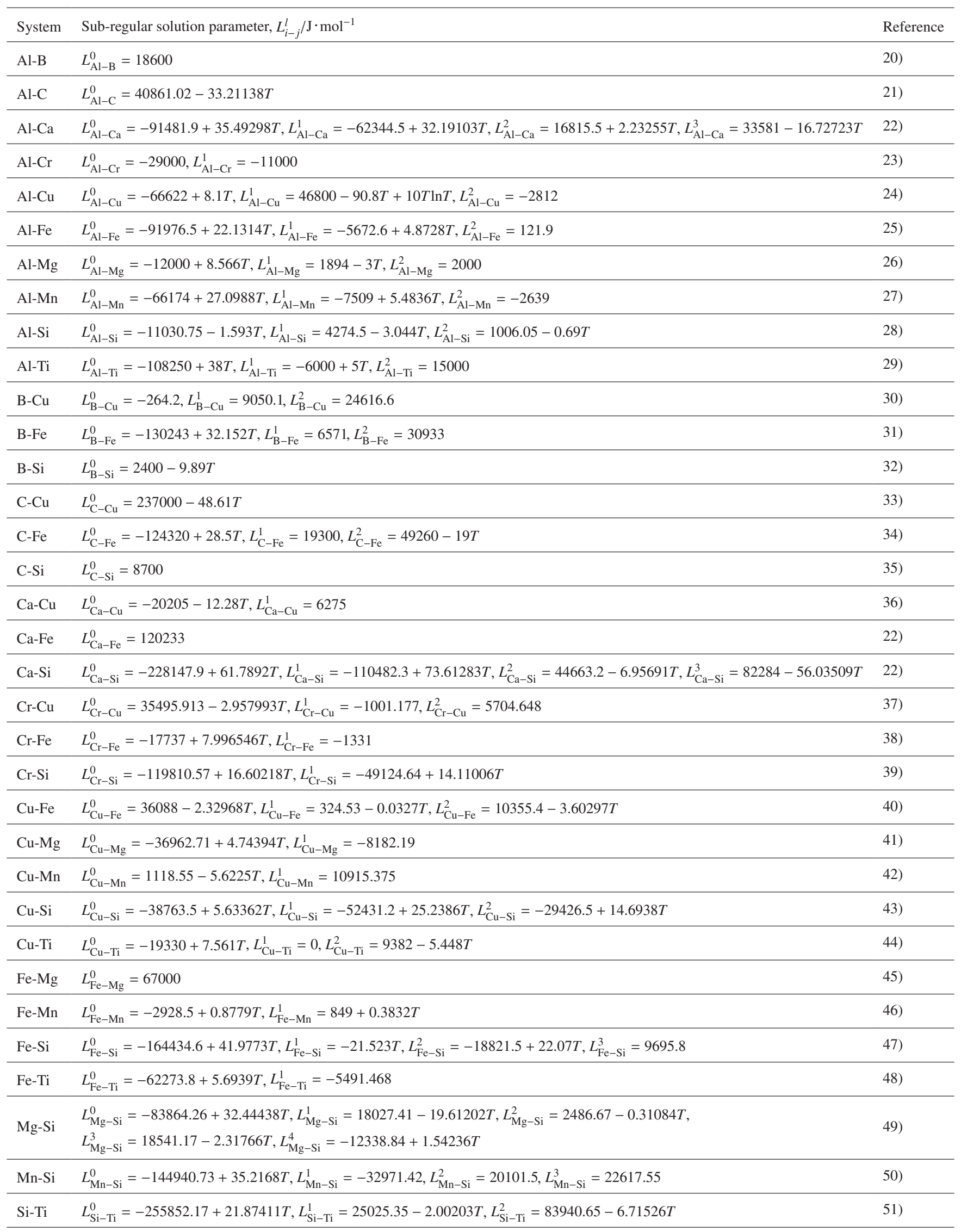

Excess Gibbs energy for the liquid phase, $L_{i-j}=x_{i} x_{j} \sum_{l=0}^{m} L_{i-j}^{l}\left(x_{i}-x_{j}\right)^{l}$

Contributions between B-C, B-Ca, B-Cr, B-Mg, B-Mn, B-Ti, C-Ca, C-Cr, C-Mg, C-Mn, C-Ti, Ca-Cr, Ca-Mg, Ca-Mn, Ca-Ti, Cr-Mg, Cr-Mn, Cr-Ti, $\mathrm{Mg}-\mathrm{Mn}, \mathrm{Mg}-\mathrm{Ti}, \mathrm{Mn}-\mathrm{Ti}$ were not included in the calculation because of the negligible effects. 
phase. The thermodynamic data for the calculations including $\mathrm{Cu}$ are also listed in Tables 2 and 3, and the effect of $\mathrm{Cu}$ addition on the purification of MG-Si was examined.

\subsection{Estimation results for purification}

\subsubsection{Purification of MG-Si}

Under solid-liquid equilibrium, the chemical potentials of the components are equivalent in both phases. Therefore, the solid solubilities of the impurities in the $\mathrm{Si}, X_{i}^{s}$, are described by the following equation.

$$
\ln \frac{X_{i}^{s}}{X_{i}^{l}}=\frac{\Delta G_{i}^{f u s}}{R T}+\ln \frac{\gamma_{i}^{l}}{\gamma_{i}^{s,}}
$$

Here, $\gamma_{i}^{s,{ }^{\circ}}$ and $\gamma_{i}^{l}$ are the activity coefficients of $i$ in the solid $\mathrm{Si}$ and the liquid phase, respectively, $X_{i}^{l}$ is the mole fraction in the liquid phase, and $\Delta G_{i}^{f u s}$ is the Gibbs energy of fusion. Note that the values of $\gamma_{i}^{s,{ }^{\circ}}$ are listed in Table 2 and are those at infinite dilution. The solid solubilities of the respective binary systems and the corresponding contents in the liquid phases were estimated and are shown in Figs. 3(a) and 4(a), respectively. The solubilities generally take maximum values in case of Si binary systems. When the liquid phase is a multicomponent system, they can be expected to decrease mainly because of the dilution of the elements in the liquid phase.

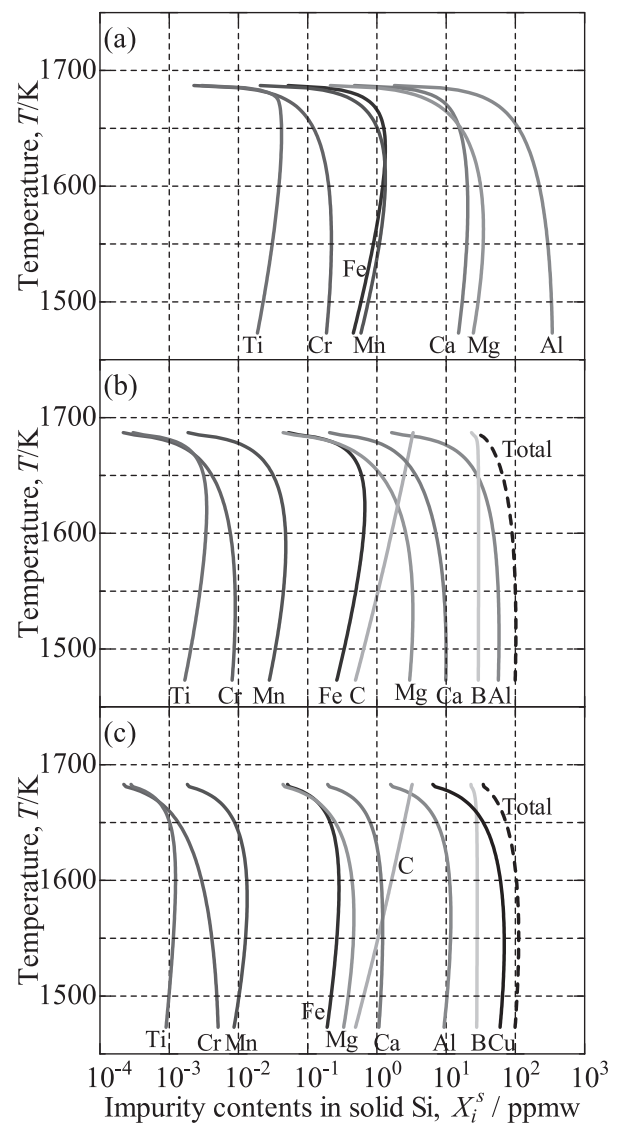

Fig. 3 Impurity contents in the solid Si estimated from the distribution between solid $\mathrm{Si}$ and liquid phase for (a) each binary $\mathrm{Si}-i$ system, (b) MG-Si, and (c) 2 mass\% Cu-added MG-Si. B and C are not shown in (a) because they did not equilibrate with the liquid phase. The initial contents of the impurities in the MG-Si are listed in Table 1.
The estimated impurity contents in the solid Si after performing the migration process on the simulated sample of MG-Si (Table 1) are shown in Fig. 3(b). The corresponding impurity contents in the liquid phase are shown in Fig. 4(b). After the migration process, the contents of the metallic impurities are considerably decreased from their initial contents in the MG-Si and are even much lower than their solid solubilities shown in Fig. 3(a). The contents of $\mathrm{Cr}, \mathrm{Mg}, \mathrm{Mn}$ and Ti become smaller than $10 \%$ of their solid solubilities in the respective binary systems after liquid phase migration above $1523 \mathrm{~K}$. The contents of $\mathrm{Al}$ and $\mathrm{Ca}$ are smaller than $20 \%$ of their binary solid solubilities. In contrast, Fe is the main component among all the impurities and thus its content is around $50 \%$ of its binary solid solubility. To discuss this reduction in impurity content in detail, the impurity contents as well as their activity coefficients in the liquid phase for MG-Si and the respective binary systems were compared at $1480-1681 \mathrm{~K}$ and are shown in Fig. 5. Note that solid-liquid equilibrium in the Si-B system is limited to just below the melting point of $\mathrm{Si}$, so the activity coefficient of $\mathrm{B}$ in the binary system was used to extrapolate that at infinite dilution. The decrease in the contents of the transition metals in solid Si from their solid solubilities in the binary systems can be considered to be mainly caused by dilution because the difference in their activity coefficients was not significant. The activity coefficient of $\mathrm{Ca}$ in MG-Si was relatively

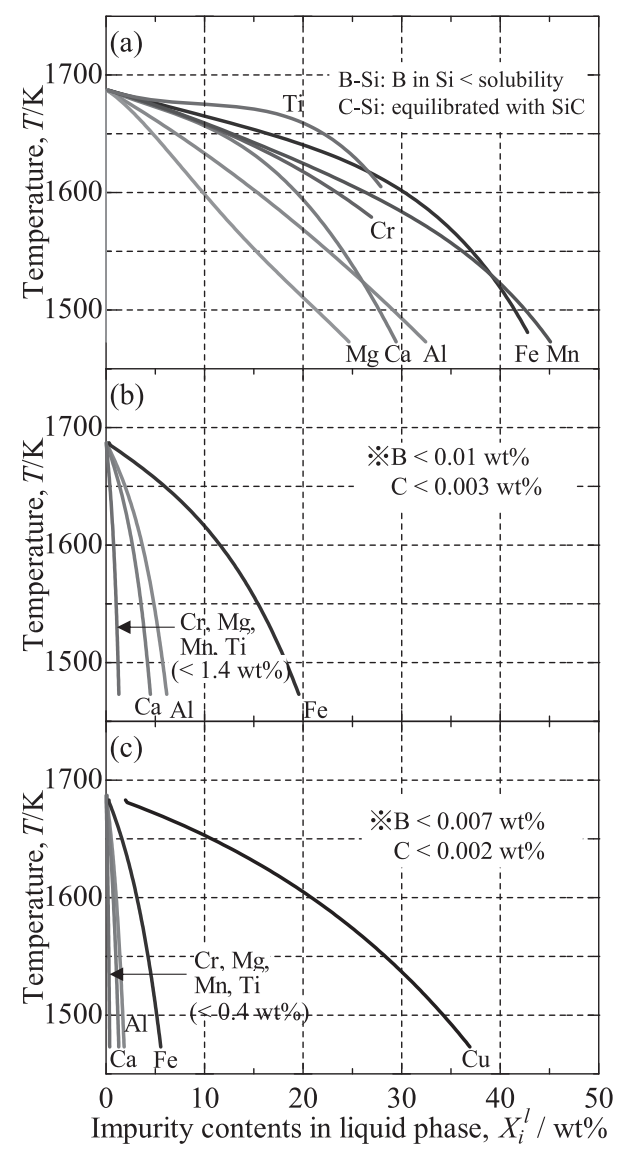

Fig. 4 Impurity contents in the liquid phase estimated from the distribution between solid $\mathrm{Si}$ and liquid phase for (a) each binary $\mathrm{Si}-i$ system, (b) MG-Si, and (c) 2 mass \% Cu-added MG-Si. B and C are not shown in (a) because they did not equilibrate with the liquid phase. The initial contents of the impurities in the MG-Si are listed in Table 1. 

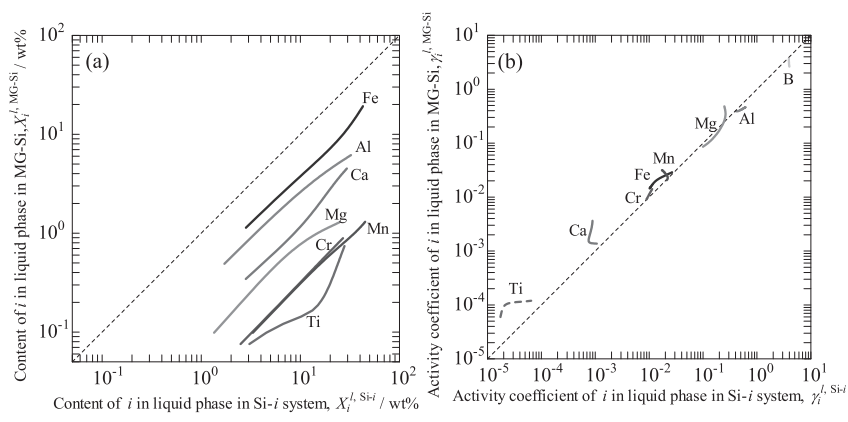

Fig. 5 Comparisons of (a) impurity contents and (b) activity coefficients in the liquid phases in the binary $\mathrm{Si}-i$ systems and MG-Si at 1480 $1681 \mathrm{~K}$. The activity coefficient of $\mathrm{Ti}$ in (b) seems to be unreliable because of inappropriate fitting of the sub-regular solution parameter for the Si-Ti system in the low activity region.

larger than that in the binary systems, mainly owing to the repulsive interaction in the $\mathrm{Ca}-\mathrm{Fe}$ system in the liquid phase (see Table 3). As a result of the significant dilution effect, the contents of $\mathrm{Ti}, \mathrm{Mn}$, and $\mathrm{Cr}$ in the solid $\mathrm{Si}$ were estimated to be less than 0.05 ppmw, which is comparable with the allowable amounts for solar cell $\mathrm{Si}$, while additional refining is inevitable for $\mathrm{Al}, \mathrm{B}$, and $\mathrm{Fe}$.

In the temperature range of the calculations of the simulated MG-Si, the total impurity content exhibited an increasing tendency with decreasing temperature, while $\mathrm{Fe}, \mathrm{Mn}$, and $\mathrm{Ti}$ had a retrograde solubility limit, the same tendency as in the binary systems. Improvement of the purification limit can be thus obtained at higher temperature, mainly owing to the decrease in the impurity content of the liquid phase. On the other hand, a lower temperature is effective in improving the yield of $\mathrm{Si}$ and heat treatment at less than $1670 \mathrm{~K}$ was found to be needed to obtain a yield of more than $90 \%$. The fraction of liquid phase should also be carefully managed through temperature control to obtain a high throughput. Although further purification is needed, the total amount of impurities in the solid $\mathrm{Si}$ was predicted to be lower than 100 ppmw over the whole temperature range, and lower than $50 \mathrm{ppmw}$ at above $1670 \mathrm{~K}$ from the initial amount of 0.747 mass \%, which is much lower than the summation of the solid solubilities of each element.

\subsubsection{Enhancement of purification of MG-Si by $\mathrm{Cu}$ addition}

Further purification by adding $\mathrm{Cu}$ to the MG-Si was also examined. $\mathrm{Cu}$ in $\mathrm{Si}$ can be easily removed by the gettering process because of the large diffusion coefficient of $\mathrm{Cu}$ in solid $\mathrm{Si}^{54)}$. Assuming that a $\mathrm{Cu}$ content of around $100 \mathrm{ppmw}$ after purification is acceptable, addition of 2 mass $\% \mathrm{Cu}$ to the MG-Si was examined. The estimated impurity content in the solid $\mathrm{Si}$ and liquid phase after the distribution is shown in Figs. 3(c) and 4(c), respectively. The relative amount of impurities in the solid $\mathrm{Si}$ obtained from their distributions without $\mathrm{Cu}$ addition at $1623 \mathrm{~K}$ is also shown in Fig. 6. For metallic impurities, the content of each impurity element was decreased to less than $40 \%$ by the addition of $\mathrm{Cu}$ at $1623 \mathrm{~K}$. Especially, the contents of $\mathrm{Al}, \mathrm{Ca}$, and $\mathrm{Mg}$ impurities were effectively decreased to less than $25 \%$. However, $\mathrm{Cu}$ addition was not effective in reducing the contents of the nonmetallic impurities, B and C. To further evaluate the effect of $\mathrm{Cu}$ addition, the impurity contents in solid $\mathrm{Si}$ and the

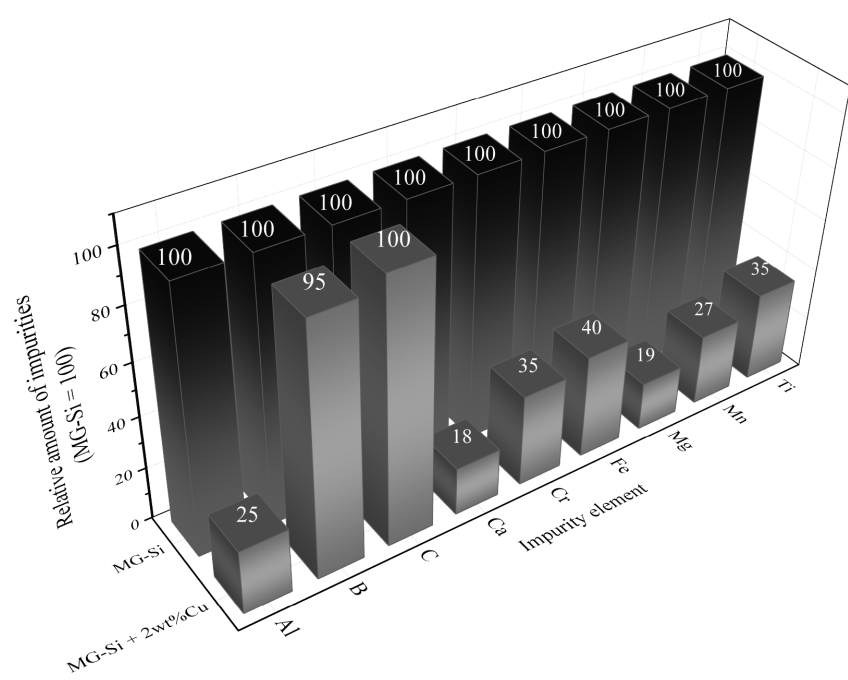

Fig. 6 Relative amounts of impurities in the solid Si at $1623 \mathrm{~K}$ estimated from the distributions for the 2 mass $\% \mathrm{Cu}$-added MG-Si from those for the MG-Si.

activity coefficients in the liquid phase were calculated and are shown in Fig. 7. At lower than $1623 \mathrm{~K}$, the activity coefficients of $\mathrm{Al}, \mathrm{Ca}$, and $\mathrm{Mg}$ decreased with increasing $\mathrm{Cu}$ content. The more effective removal of these elements than that of the other impurities was thus obtained both through dilution and interactions between $\mathrm{Cu}-\mathrm{Al}, \mathrm{Cu}-\mathrm{Ca}$, and $\mathrm{Cu}-\mathrm{Mg}$. At $1673 \mathrm{~K}$, the activity coefficients of all the elements were almost the same regardless of $\mathrm{Cu}$ content, resulting in a decrease in impurity content only from the effect of dilution. Although a certain decrease in impurity content was predicted, further treatment would still be required for $\mathrm{Al}, \mathrm{Ca}$, and $\mathrm{Mg}$. If we presume direct refining starting from the melting of the MG-Si and subsequent solidification process, pre-treatment by oxidizing refining should be effective because these elements are more easily oxidized than $\mathrm{Si}$. In that case, the contents of $\mathrm{Al}, \mathrm{Ca}$, and $\mathrm{Mg}$ could be decreased to less than 100 ppmw using $\mathrm{SiO}_{2}$-rich slag ${ }^{55)}$ after the slagging process. Application of the proposed migration process with $\mathrm{Cu}$ addition to the refined MG-Si should result in $\mathrm{Al}$, $\mathrm{Ca}$, and $\mathrm{Mg}$ contents below the allowable levels.

\section{Liquid Phase Migration in Fe-added Si}

\subsection{Experimental method}

To study the migration behavior of the impurity enriched liquid phases dispersed in the solid $\mathrm{Si}$, an Fe-added Si plate was subjected to heat treatment under a temperature gradient. Figure 8(a) shows the experimental apparatus used for the heat treatment. The temperature gradient was applied to the sample plate in the downward direction, obtained by heating the sample from the top using an infrared image furnace. This enabled buoyancy convection in the liquid to be suppressed.

A 0.2 mass $\%$ Fe-added Si plate $(\phi 10 \mathrm{~mm})$ was prepared by melting Si lumps (6 N) and Fe wire $(99.9 \%)$ in a graphite crucible, followed by quenching and slicing. The plate was polished to obtain mirror faces and a thickness of 0.4 $0.6 \mathrm{~mm}$. After the plate was fixed on the hollow graphite holder, the chamber was evacuated and the sample was 

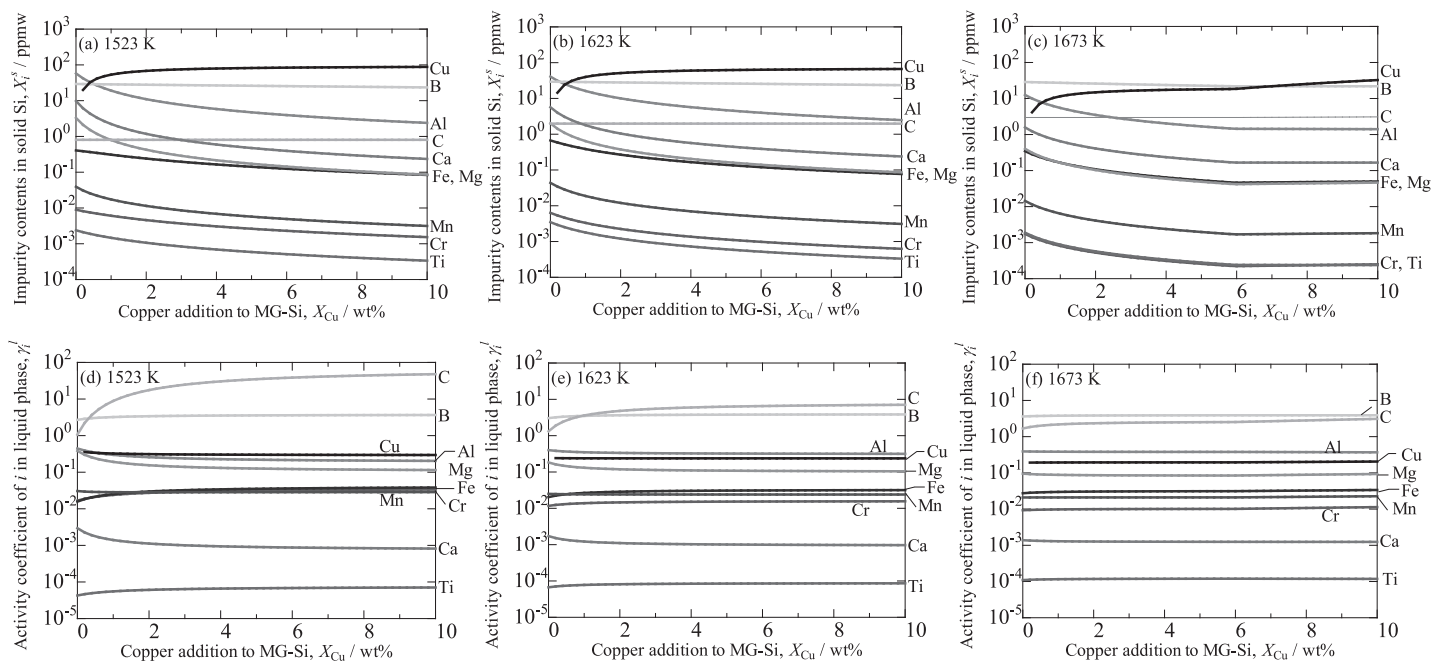

Fig. 7 Change in (a)-(c) impurity contents in the solid Si and (d)-(f) activity coefficients in the liquid phase upon addition of $\mathrm{Cu}$.

(a)

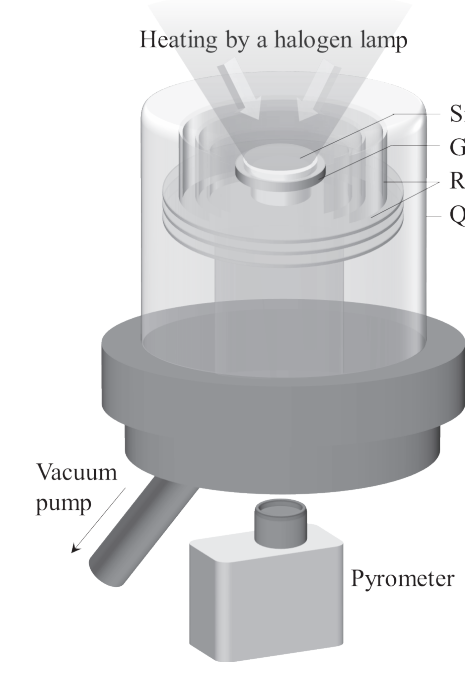

(b)

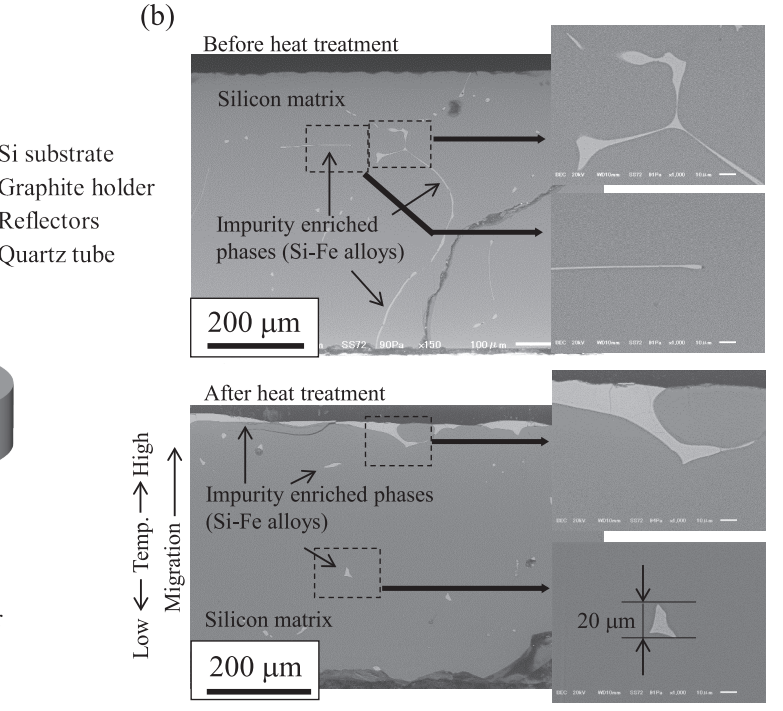

Fig. 8 (a) Schematic illustration of experimental apparatus for migration of the impurity enriched liquid phases and (b) cross sections of the samples before and after heat treatment at $1573 \mathrm{~K}$ for $15 \mathrm{~min}$.

heated under vacuum. The temperature of the bottom of the Si plate was measured using a single color pyrometer $(\lambda=$ $0.9 \mu \mathrm{m}$, IR-C S1SYA, CHINO Co.). The heating rate of the sample above the eutectic temperature of $\mathrm{Si}$ and $\mathrm{FeSi}_{2}$ $(1480 \mathrm{~K})$ was carefully controlled to over $400 \mathrm{~K} / \mathrm{min}$ to minimize the migration during heating. The sample was then held at $1523-1623 \mathrm{~K}$ for $2.5-30 \mathrm{~min}$ to cause the liquid phases to migrate in the solid $\mathrm{Si}$.

Before and after the heat treatment, the distribution of the impurity enriched phases was investigated by exploiting the infrared transmission property of Si. The Si plate was placed on an $\mathrm{Al}$ mirror, and the position of the impurity enriched phases in the thickness direction was measured by reflective observation using an infrared optical microscope equipped with an InGaAs camera (XS 2825, Xenics Co.). For each sample, the migration distance was determined at more than five positions to ensure reliability, and the average migration velocity was used for the evaluation.

Accurate measurement of the temperature gradient in the sample was difficult because the temperature difference between both surfaces was very small in the thin plate sample. Therefore, the gradient was estimated based on the sample being heated from the top and cooled from the bottom by radiation. By assuming a steady-state in which the conductive heat flux in the solid Si was balanced with the radiation from the bottom surface as well as the conductive heat flux of the liquid phases, their relations are expressed by the following equation if the temperature gradient in each phase is constant.

$$
\varepsilon \sigma T^{4}=k_{s} G_{s}=k_{l} G_{l}
$$

Here, $\varepsilon$ is the emissivity of solid $\mathrm{Si}\left(\varepsilon_{\mathrm{Si}}=0.65^{56)}\right), \sigma$ is the Stefan-Boltzmann constant $\left(5.7 \times 10^{-8} \mathrm{~W} \cdot \mathrm{m}^{-2} \cdot \mathrm{K}^{-4}\right), T$ is the temperature at the bottom surface of the sample, $k_{\mathrm{s}}$ (or $k_{l}$ ) and $G_{s}$ (or $G_{l}$ ) are the thermal conductivity and temperature gradient in the solid $\mathrm{Si}$ (or liquid phase), respectively. $k_{l}$ was obtained from a model for a binary system ${ }^{57)}$ using the thermal conductivities of the pure components ${ }^{58,59)}$ and their 
molar volumes ${ }^{60)}$. In some samples, the temperature gradient was decreased by coating the bottom surface of the Si plate with $\mathrm{Al}_{2} \mathrm{O}_{3}\left(\varepsilon_{\mathrm{Al} 2 \mathrm{O} 3}=0.40^{61)}\right)$ to change the radiation.

\subsection{Migration behavior results}

Figure 8(b) shows an example of the cross sections of the samples before and after the heat treatment. The impurity enriched phases dispersed in the solid $\mathrm{Si}$ before the heat treatment existed at the grain boundaries in the shape of thin films (a few $\mu \mathrm{m}$ in thickness). After the heat treatment, the impurity phases migrated to the high-temperature side, and became rounded and agglomerated with the sizes of about $10-100 \mu \mathrm{m}$ in diameter. This change in shape likely arose from the minimization of the interfacial area of the phases to decrease the energy of the solid-liquid interface.

The measured migration velocity of the liquid phase at liquidus composition at the experimental temperatures is summarized in Table 4 . The migration velocity at $1548 \mathrm{~K}$ without $\mathrm{Al}_{2} \mathrm{O}_{3}$ coating was equivalent regardless of heat treatment time. A constant migration velocity was obtained throughout the heat treatment because the temperature difference calculated using eq. (2) was estimated to be less than $7 \mathrm{~K}$ from the thickness of the sample. Figure 9 shows the temperature dependency of the migration velocity. The migration velocity increased with temperature. A significant increase in the velocity was observed above $1598 \mathrm{~K}$, suggesting a decrease in the difference between the Si contents of the solid and liquid phases caused by the increase in the Si content of the liquid phase.

The decrease in migration velocity caused by coating the bottom surface of the sample with $\mathrm{Al}_{2} \mathrm{O}_{3}$ was also confirmed, which was caused by the decrease in radiation from the low temperature surface. The relationship between the migration velocity at 1548 and $1573 \mathrm{~K}$ and the temperature gradient in the liquid phase estimated from eq. (2) is shown in Fig. 10. The migration velocity was found to be nearly proportional to the temperature gradient at both temperatures.

\subsection{Discussion}

\subsubsection{Kinetic model for liquid phase migration}

The basic principle of the migration of the liquid phase is identical to that of the temperature gradient zone melting (TGZM) method first proposed by Pfann ${ }^{62)}$. The interfaces of the liquid phases dispersed in the solid Si matrix are as- sumed to be at solid-liquid equilibrium at the treatment temperature. The temperature gradient in the liquid phases allows the concentration gradient, leading to their mass transfer in the melt. Dissolution of Si into the liquid phase is then expected at the high-temperature interface to maintain its $\mathrm{Si}$ saturation, while the precipitation of $\mathrm{Si}$ occurs at the low temperature interface. This continuous dissolution and precipitation of Si through the liquid phase causes the liquid phase to spontaneously migrate towards the higher temperature side. Here, the convection in the liquid phase is assumed to have been negligible during the migration under the decreasing temperature gradient in the downward direction. Additionally, the reactions at the interfaces were pre-

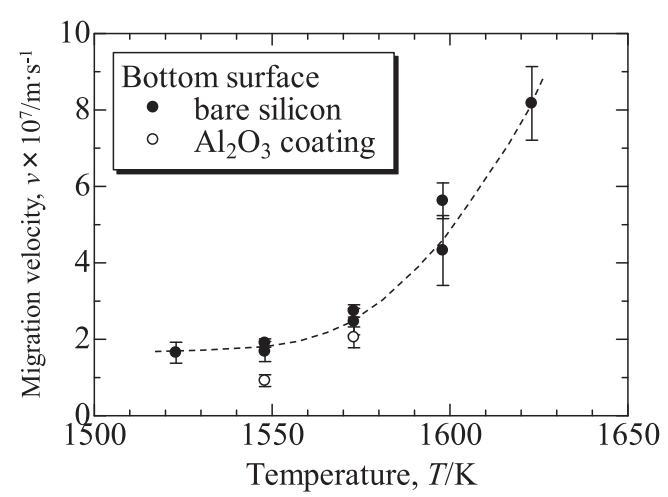

Fig. 9 Temperature dependence of migration velocity of liquid phase in solid $\mathrm{Si}$.

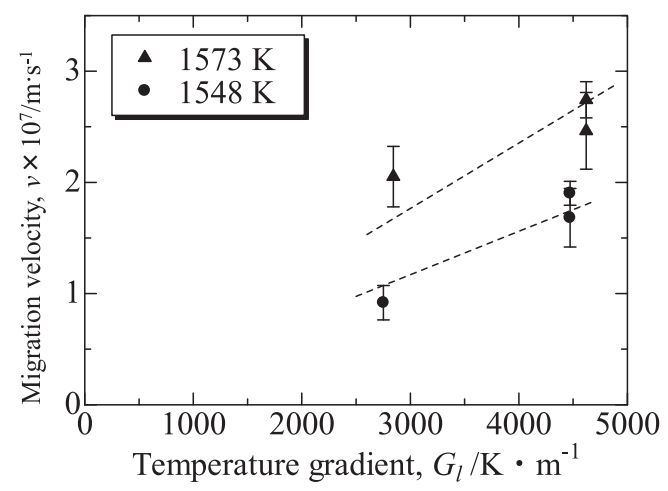

Fig. 10 Relationship between migration velocity and temperature gradient in liquid phase.

Table 4 Migration velocities of molten Fe-Si in the solid Si measured from infrared transmission observations.

\begin{tabular}{|c|c|c|c|c|c|c|}
\hline No. & Temperature, $T / \mathrm{K}$ & Time, $t / \min$ & $\begin{array}{l}\text { Temperature gradient in } \\
\text { liquid, } G_{l} \times 10^{-3} / \mathrm{K} \cdot \mathrm{m}^{-1}\end{array}$ & $\begin{array}{l}\text { Migration distance, } \\
l \times 10^{6} / \mathrm{m}\end{array}$ & $\begin{array}{l}\text { Migration velocity, } \\
v \times 10^{7} / \mathrm{m} \cdot \mathrm{s}^{-1}\end{array}$ & Remarks \\
\hline V1 & 1548 & 15 & 4.5 & $151 \pm 24$ & $1.68 \pm 0.26$ & \\
\hline $\mathrm{V} 3$ & 1548 & 30 & 2.8 & $165 \pm 28$ & $0.917 \pm 0.16$ & $\mathrm{Al}_{2} \mathrm{O}_{3}$-coated \\
\hline V4 & 1573 & 15 & 4.6 & $222 \pm 31$ & $2.46 \pm 0.35$ & \\
\hline V5 & 1573 & 15 & 4.6 & $247 \pm 15$ & $2.74 \pm 0.16$ & \\
\hline V6 & 1573 & 15 & 2.8 & $185 \pm 25$ & $2.05 \pm 0.27$ & $\mathrm{Al}_{2} \mathrm{O}_{3}$-coated \\
\hline V7 & 1523 & 30 & 4.3 & $297 \pm 49$ & $1.65 \pm 0.27$ & \\
\hline V8 & 1598 & 15 & 4.8 & $506 \pm 42$ & $5.62 \pm 0.47$ & \\
\hline V9 & 1598 & 15 & 4.8 & $389 \pm 82$ & $4.32 \pm 0.91$ & \\
\hline V10 & 1623 & 2.5 & 4.9 & $123 \pm 14$ & $8.17 \pm 0.96$ & \\
\hline
\end{tabular}


sumably fast enough under the high experimental temperature. The migration was thus assumed to be controlled by the diffusion in the liquid phase. Under the steady-state, the flux of component $i$ ( $\mathrm{Si}$ or $\mathrm{Fe}$ ) in the liquid phase, $J_{i}$, can be described by the following equation.

$$
J_{i}=-D^{\text {liquid }} \frac{\partial C_{i}^{\text {liquid }}}{\partial x}
$$

Here, $D^{\text {liquid }}$ is the interdiffusion coefficient in the liquid phase and $C_{i}^{\text {liquid }}$ is the concentration of $i$ in the liquid phase per unit volume. The concentration gradient, $\partial C_{i}^{\text {liquid }} / \partial x$, can be derived using the reciprocal of the liquidus line, $m$ (= $\left.\partial C_{i}^{\text {liquid }} / \partial T\right)$, and the temperature gradient, $G_{l}$.

$$
J_{i}=-D^{\text {liquid }} m G_{l}
$$

If the flux is equivalent to the migration velocity, that is, the solid-liquid interface stays in the equilibrium state, and if the difference in molar volume between the solid and liquid phases is negligible, the migration velocity, $v$, can be expressed by the following equation.

$$
v\left(C_{\mathrm{Si}}^{\text {solid }}-C_{\mathrm{Si}}^{\text {liquid }}\right)=D^{\text {liquid }} m G_{l}
$$

where $C_{\mathrm{Si}}^{\text {solid }}$ is the concentration of $\mathrm{Si}$ in the solid phase per unit volume. The migration velocity roughly proportional to the temperature gradient found in Fig. 10 can be thus explained by the diffusion controlled process. However, $\mathrm{Si}$ is known to show an abnormal liquid phase transition, namely, the density of $\mathrm{Si}$ in the liquid phase is larger than that in the solid phase, which causes expansion during solidification when the $\mathrm{Si}$ content of the liquid phase is high such as in this work (>75 mol\% Si), and the left hand side of eq. (4) to become negative. To solve this problem, we assume that during the solidification process: (1) the Si flux during diffusion through the liquid phase is consumed by the hypothetical pure liquid $\mathrm{Si}$, and (2) the hypothetical liquid transits to form solid Si with expansion, and newly propose eq. (5) to express the growth rate from the abnormal liquid,

$$
\begin{aligned}
v \frac{V_{l}^{*}}{V_{s}}\left(C_{\mathrm{Si}}^{\text {liquido }}-C_{\mathrm{Si}}^{\text {liquid }}\right) & =v \frac{V_{l}^{*}}{V_{s}}\left(\frac{V_{s}}{V_{l}^{*}} C_{\mathrm{Si}}^{\text {solid }}-C_{\mathrm{Si}}^{\text {liquid }}\right) \\
& =D^{\text {liquid }} m G_{l}
\end{aligned}
$$

where $V_{s}$ and $V_{l}^{*}$ are the molar volume of $\mathrm{Si}$ in the solid and liquid phases at the composition of the solid phase, respec- tively, and $C_{\mathrm{Si}}^{\text {liquido }}$ is the concentration of $\mathrm{Si}$ in its pure liquid phase per unit volume. The equation can be also expressed using the mole fraction of $\mathrm{Si}$ in the solid and liquid phases, $X_{\mathrm{Si}}^{s}$ and $X_{\mathrm{Si}}^{l}$, respectively.

$$
v\left(\frac{V_{l}}{V_{s}} X_{\mathrm{Si}}^{s}-\frac{V_{l}^{*}}{V_{s}} X_{\mathrm{Si}}^{l}\right)=D^{\text {liquid }} m^{\prime} G_{l}
$$

Here, $V_{l}$ represents the molar volume of the liquid phase at the liquidus composition and $m^{\prime}$ is the reciprocal of the liquidus line obtained by $\partial X_{\mathrm{Si}}^{l} / \partial T$. The interdiffusion coefficient in the liquid phase at the liquidus composition can be thus obtained from the migration velocity.

\subsubsection{Evaluation of interdiffusion coefficient}

In the evaluation of the diffusion coefficient, $V_{s}$ and $V_{l}^{*}$ were assumed to be equivalent to the molar volumes of pure solid and liquid $\mathrm{Si}^{60,63)}$, respectively, and $V_{l}$ at each liquidus composition was estimated from the values measured at $1820 \mathrm{~K}$ by Mizuno et al. ${ }^{64)} \mathrm{m}^{\prime}$ was obtained from the liquidus for solid $\mathrm{Si}$ in the Fe-Si system ${ }^{65)}$. The interdiffusion coefficients obtained via eqs. (4) and (5) are summarized in Table 5 alongside the physicochemical properties used for the evaluation. The interdiffusion coefficient obtained from eq. (5) increases with temperature, while that from eq. (4) shows the opposite tendency. Thus, eq. (5) was found to be reliable even at high $\mathrm{Si}$ content in the liquid phase, at which the effect of the density difference on eq. (4) is inevitable.

According to Darken ${ }^{66)}$, the interdiffusion coefficient for a binary $i-j$ system is described by the following equation.

$$
D=\left(X_{j} D_{i}^{0}+X_{i} D_{j}^{0}\right)\left(1+X_{i} \frac{d \ln \gamma_{i}}{d X_{i}}\right)
$$

where $D_{i}^{0}$ represents the self-diffusion coefficient of component $i$, and $\gamma_{i}$ represents the activity coefficient of $i$ in the binary $i-j$ system. $D_{\mathrm{Si}}^{0}$ and $D_{\mathrm{Fe}}^{0}$ were obtained from the literature $^{67,68)}$ and $d \ln \gamma_{i} / d X_{i}$ at the liquidus composition was calculated from the excess Gibbs energy of the liquid phase ${ }^{69)}$. The estimated interdiffusion coefficient at the liquidus composition obtained from eq. (6) is shown in Fig. 11 with the measured values obtained from eq. (5). The composition dependence of the diffusion coefficient calculated with eq. (5) was roughly reproduced by eq. (6).

\subsubsection{Diffusion coefficient in various Si-metal systems}

The relation between the interdiffusion coefficients obtained from eq. (5) and the reciprocal of temperature is

Table 5 Measured interdiffusion coefficient at liquidus composition and physicochemical properties used for the evaluation.

\begin{tabular}{lllllll}
\hline No. & $\frac{\partial X_{\mathrm{Si}}^{l}}{\partial T} \times 10^{4} / \mathrm{K}^{-1}$ & $\frac{V_{l}}{V_{s}}$ & $\frac{V_{l}^{*}}{V_{s}}$ & $X_{\mathrm{Si}}^{l}$ & $\begin{array}{l}D^{\text {liquid }} \times 10^{9} / \mathrm{m}^{2} \cdot \mathrm{s}^{-1} \\
\text { obtained from eq. }(4)\end{array}$ & $\begin{array}{l}D^{\text {liquid }} \times 10^{9} / \mathrm{m}^{2} \cdot \mathrm{s}^{-1} \\
\text { obtained from eq. }\end{array}$ \\
\hline V1 & 8.30 & 0.823 & 0.891 & 0.782 & 1.9 & 5.7 \\
\hline V2 & 8.30 & 0.823 & 0.891 & 0.782 & 2.1 & 6.5 \\
\hline V3 & 8.30 & 0.823 & 0.891 & 0.782 & 1.7 & 5.1 \\
\hline V4 & 9.93 & 0.836 & 0.893 & 0.807 & 1.6 & 6.2 \\
\hline V5 & 9.93 & 0.836 & 0.893 & 0.807 & 1.7 & 8.9 \\
\hline V6 & 9.93 & 0.836 & 0.893 & 0.807 & 2.1 & 7.4 \\
\hline V7 & 7.37 & 0.814 & 0.889 & 0.763 & 2.6 & 9.9 \\
\hline V8 & 12.2 & 0.849 & 0.895 & 0.834 & 1.4 & 7.6 \\
\hline V9 & 12.2 & 0.849 & 0.895 & 0.834 & 1.1 & 9.4 \\
\hline V10 & 15.3 & 0.864 & 0.897 & 0.867 & $<0$ & \\
\hline
\end{tabular}


shown in Fig. 12 with the reported interdiffusion coefficients in $\mathrm{Si}-\mathrm{Al}^{70,71)}, \mathrm{Si}-\mathrm{Au}^{72)}$, and $\mathrm{Si}-\mathrm{Sn}^{73)}$ systems. Note that the reported diffusion coefficients measured using the TGZM technique $^{71-73)}$ were recalculated using eq. (5). The molar volumes of the $\mathrm{Si}-\mathrm{Al}$ and $\mathrm{Si}-\mathrm{Au}$ systems were assumed to obey the additivity of the pure components ${ }^{60)}$. The interdiffusion coefficients obtained for the $\mathrm{Si}$-Fe system were almost on the same order of those of the $\mathrm{Si}-\mathrm{Al}$ and $\mathrm{Si}-\mathrm{Au}$ systems, although the temperature ranges were different. However, the measured values are much larger than those for the Si-Sn system. Because $\mathrm{Si}$ atoms occupy substitutional sites in these binary alloys, their diffusivity in $\mathrm{Si}$ is speculated to increase in the order of decreasing difference in atomic radius. Figure 13 shows the relationship between the atomic radius difference and interdiffusion coefficient, where each atomic radius used is that for the pure liquid at its melting temperature (Si: $1.24 \AA^{74)}$, Fe: $1.275 \AA^{75)}$, Al: $1.48 \AA^{76)}$, Au: $1.425 \AA^{76)}$, Sn: $1.635 \AA^{76)}$ ). Although the temperature and the composition affect the diffusivity, a decreasing tendency was confirmed in the order $\mathrm{Si}-\mathrm{Fe}, \mathrm{Si}-\mathrm{Au}$, $\mathrm{Si}-\mathrm{Al}, \mathrm{Si}-\mathrm{Sn}$.

\subsubsection{Application of the migration process}

Finally, the application of the migration process to the direct synthesis of Si wafer from MG-Si as shown in Fig. 2 is discussed. The process enabled the impurity enriched liquid phase to be terminated at the high-temperature surface, which was controlled by the diffusion in the liquid phase. The maximum obtained migration velocity was $8.17 \times$

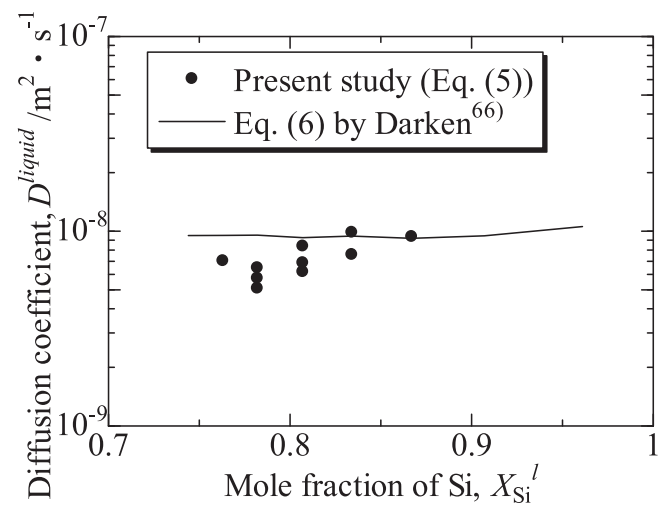

Fig. 11 Compositional dependence of interdiffusion coefficient along the liquidus composition saturated with $\mathrm{Si}$ in the $\mathrm{Fe}-\mathrm{Si}$ system with estimation at $1498-1673 \mathrm{~K}$ by eq. $(6)^{66)}$.

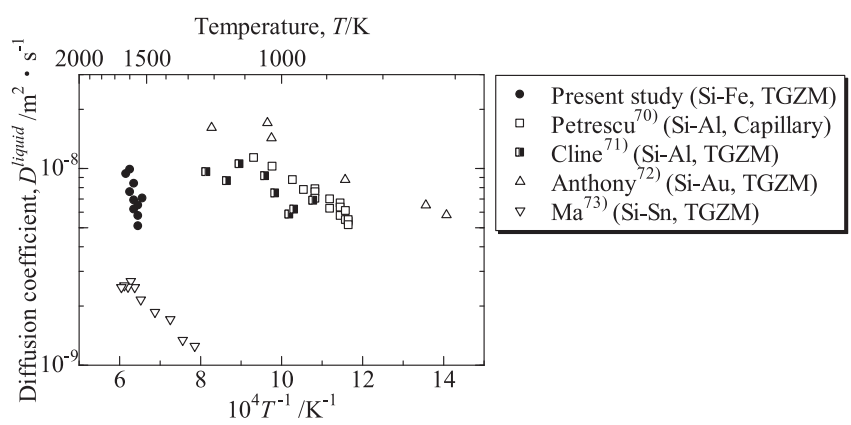

Fig. 12 Determined interdiffusion coefficient for $\mathrm{Si}-\mathrm{Fe}$ system and values reported for various systems. The reported values obtained by the TGZM method $^{71-73)}$ were recalculated using eq. (5).
$10^{-7} \mathrm{~m} / \mathrm{s}$ at $1623 \mathrm{~K}$. If the thickness of the $\mathrm{Si}$ wafer is $150 \mu \mathrm{m}$, such a high migration velocity would enable all of the liquid phases in the wafer to be terminated at the high-temperature surface within only 3 min. This result confirms the feasibility of directly upgrading of Si from a melt bath of MG-Si.

\section{Conclusions}

The upgrading of Si by a metallurgical process was examined by both thermodynamic and experimental assessments of the liquid phase migration technique. The results are summarized as follows;

(1) The purification limit of MG-Si at 1480-1687 K was assessed by thermodynamic evaluation. The estimated impurity contents were much lower than their solid solubilities of each binary system. The contents of most of the transition metals (Cr, Mn, and Ti) were found to be lowered to less than 0.05 ppmw. The contents of the other impurities (Al, $\mathrm{Fe}, \mathrm{Mg}$, and $\mathrm{Ca}$ ) were higher than the allowable levels. $\mathrm{Cu}$ addition decreased the impurity contents to less than $40 \%$ at $1623 \mathrm{~K}$.

(2) We newly proposed the following equation to express the solidification of Si from the Si-based liquid under diffusion control with the modification of the density difference between the solid and liquid.

$$
v \frac{V_{l}^{*}}{V_{s}}\left(\frac{V_{s}}{V_{l}^{*}} C_{\mathrm{Si}}^{\text {solid }}-C_{\mathrm{Si}}^{\text {liquid }}\right)=D^{\text {liquid }} m G_{l}
$$

The migration behavior of Fe-Si liquid phases dispersed in the solid Si at 1523-1623 K was evaluated and was found to be controlled by diffusion. The maximum migration velocity of $8.17 \times 10^{-7} \mathrm{~m} / \mathrm{s}$ at $1623 \mathrm{~K}$ allows the migration process to be accomplished within only 3 min for a $150-\mu \mathrm{m}$ wafer.

\section{Acknowledgements}

This research was partly supported by a Grant-in-Aid for

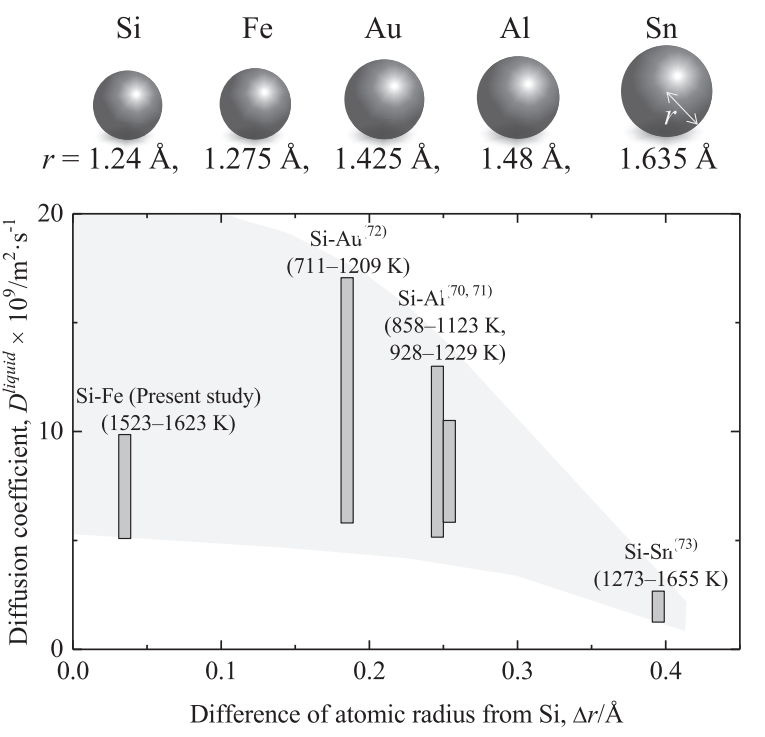

Fig. 13 Relationship between interdiffusion coefficients of binary Si- $i$ systems and difference in their atomic radii at their melting point. 
Exploratory Research (Grant No. JP24656455), from Japan Society for the Promotion of Science.

\section{REFERENCES}

1) H. Schweickert, K. Reuschel and H. Gutsche: U.S. Patent (1961) 3011877.

2) H. Gutsche: U.S. Patent (1962) 3042494.

3) H.A. Aulich and F.W. Schulze: Prog. Photovolt. Res. Appl. 10 (2002) 141-147.

4) T. Noda: Proc. Flat-Plate Solar Array Project Workshop on Low-Cost Polysilicon for Terrestrial Photovoltaic Solar Cell Applications, (Las Vegas, 1985) pp. 213-231.

5) N. Yuge, Y. Sakaguchi, H. Terashima and F. Aratani: J. Jpn. Inst. Metals 61 (1997) 1094-1100.

6) K. Suzuki, K. Sakaguchi, T. Nakagiri and N. Sano: J. Jpn. Inst. Metals 54 (1990) 161-167.

7) K. Suzuki, T. Kumagai and N. Sano: ISIJ Int. 32 (1992) 630-634.

8) T. Ikeda and M. Maeda: Mater. Trans., JIM 37 (1996) 983-987.

9) N. Nakamura, H. Baba, Y. Sakaguchi and Y. Kato: Mater. Trans. 45 (2004) 858-864.

10) T. Yoshikawa and K. Morita: Metall. Mater. Trans., B 36B (2005) 731-736.

11) T. Yoshikawa and K. Morita: J. Crys. Growth 311 (2009) 776-779.

12) T. Yoshikawa and K. Morita: ISIJ Int. 45 (2005) 967-971.

13) F.A. Trumbore: Bell Syst. Tech. J. 39 (1960) 205-233.

14) T.F. Ciszek: Mater. Res. Bull. 7 (1972) 731-737.

15) T. Yoshikawa and K. Morita: J. Electrochem. Soc. 150 (2003) G465-G468.

16) T. Yoshikawa and K. Morita: Metall. Mater. Trans., B 36B (2005) 731-736.

17) T. Yoshikawa, K. Morita, S. Kawanishi and T. Tanaka: J. Alloy. Compd. 490 (2010) 31-41.

18) S. Kawanishi and T. Yoshikawa: Mater. Trans., 58 (2017) 450-452.

19) T. Yoshikawa and K. Morita: J. Phys. Chem. Solids 66 (2005) 261-265.

20) T. Yoshikawa and K. Morita: J. Jpn. Inst. Metals 68 (2004) 390-394.

21) J. Gröbner, H.L. Lukas and F. Aldinger: J. Alloy. Compd. 220 (1995) 8-14.

22) J.C. Anglezio, C. Servant and I. Ansara: Calphad 18 (1994) 273-309.

23) I. Ansara, A. T. Sinsdale and M. H. Rand: COST 507 Thermochemical database for light metal alloys, vol. 2 (1998) pp. 23-27.

24) I. Ansara, A. T. Sinsdale and M. H. Rand, COST 507 Thermochemical database for light metal alloys, vol. 2 (1998) pp. 28-33.

25) M.H.G. Jacobs and R. Schmid-Fetzer: Calphad 33 (2009) 170-178.

26) N. Saunders: Calphad 14 (1990) 61-70.

27) ̊.. Jansson: Metall. Trans., A, Phys. Metall. Mater. Sci. 23A (1992) 2953-2962.

28) J.L. Murray and A.J. McAlister: Bull. Alloy Phase diagrams 5 (1984) 74-84.

29) I. Ansara, A. T. Sinsdale and M. H. Rand, COST 507 Thermochemical database for light metal alloys, vol. 2 (1998) pp. 89-94.

30) W.W. Zhang, Y. Du, H. Xu, W. Xiong, Y. Kong, W. Sun, F. Pan and A. Tang: J. Phase Equilibria Diffus. 30 (2009) 480-486.

31) T. Van Rompaey, K.C. Hari Kuma and P. Wollants: J. Alloy. Compd. 334 (2002) 173-181.

32) T. Yoshikawa and K. Morita: Mater. Trans. 46 (2005) 1335-1340.

33) L.L. Oden and N.A. Gokcen: Metall. Mater. Trans., B 23B (1992) 453-458.

34) P. Gustafson: Scand. J. Metall. 14 (1985) 259-267.

35) S. Kawanishi, T. Yoshikawa and T. Tanaka: Mater. Trans. 50 (2009) 806-813.

36) D.J. Chakrabarti and D.E. Laughlin: Bull. Alloy Phase diagrams 5 (1984) 570-576

37) N. Saunders: Mater. Sci. Technol. 3 (1987) 671-673.

38) B.J. Lee: Calphad 17 (1993) 251-268.

39) C.A. Coughanowr, I. Ansara and H.L. Lukas: Calphad 18 (1994) 125-140.
40) I. Ansara, A. T. Sinsdale and M. H. Rand, COST 507 Thermochemical database for light metal alloys, vol. 2 (1998) pp. 165-167.

41) C.A. Coughanowr, I. Ansara, R. Luoma, M. Hämäläinen and H.L. Lukas: Z. Metallk. 82 (1991) 574-581.

42) C. He, Y. Du, H.L. Chen, S. Lui, H. Xu, Y. Ouyang and Z.K. Liu: J. Alloy. Compd. 457 (2008) 233-238.

43) T. Miki, N. Ogawa, T. Nagasaka and M. Hino: ISIJ Int. 42 (2002) 1071-1076.

44) K.C.H. Kumar, I. Ansara, P. Wollants and L. Dulaey: Z. Metallk. 87 (1996) 666-672.

45) A.A. Nayeb-Hashemi, J.B. Clark and L.J. Swartzendruber: Bull. Alloy Phase diagrams 6 (1985) 235-238.

46) V.T. Witusiewicz, F. Sommer and E.J. Mittemeijer: J. Phase Equilibria Diffus. 25 (2004) 346-354.

47) J. Lacaze and B. Sundman: Metall. Trans., A, Phys. Metall. Mater. Sci. 22A (1991) 2211-2223.

48) I. Ansara, A. T. Sinsdale and M. H. Rand, COST 507 Thermochemical database for light metal alloys, vol. 2 (1998) pp. 205-207.

49) H. Feufel, T. Gödecke, H.L. Lukas and F. Sommer: J. Alloy. Compd. 247 (1997) 31-42.

50) P.Y. Chevalier, E. Fischer and A. Rivet: Calphad 19 (1995) 57-68.

51) H.J. Seifert, H.L. Lukas and G. Petzow: Z. Metallk. 87 (1996) 2-13.

52) O. Kubaschewski, C. B. Alcock and P. J. Spencer: Materials Thermochemistry 6th Ed., (Pergamon press, New York, 1993) p. 308.

53) J.R. Davis, A. Rohatgi, R.H. Hopkins, P.D. Blais, P. Rai-Choudhury, J.R. Mccormick and H.C. Mollenkopf: IEEE Trans. Electron Devices ED-27 (1980) 677-687.

54) E.R. Weber: Appl. Phys., A Mater. Sci. Process. 30 (1983) 1-22.

55) K. Kume, K. Morita, T. Miki and N. Sano: ISIJ Int. 40 (2000) 561-566.

56) B. Sopori, W. Chen, J. Madjdpur and N.M. Ravindra: J. Electron. Mater. 28 (1999) 1385-1389.

57) M.P. Saksena and Harminder: Chem. Phys. Lett. 25 (1974) 445-448.

58) H. Kobatake, H. Fukuyama, T. Tsukada and S. Awaji: Meas. Sci. Technol. 21 (2010) 025901.

59) T. Nishi, H. Shibata, H. Ohta and Y. Waseda: Metall. Mater. Trans., A 34A (2003) 2801-2807.

60) T. Iida and R. I. L. Guthrie: The Physical Properties of Liquid Metals, Clarendon Press, 1st ed., (Oxford University Press Inc., New York $1993)$ p. 6, 7, 71.

61) Table of emissivity, CHINO corporation. http://www.chino.co.jp/ support/technique/thermometers/housyaritsu.html, (accessed 2017-07-03)

62) W.G. Pfann: T. Am. I. Min. Met. Eng. 9 (1955) 961-964.

63) K. Ohsaka, S.K. Chung, W.K. Rhim and J.C. Holzer: Appl. Phys. Lett. 70 (1997) 423-425.

64) A. Mizuno, H. Kawauchi, M. Tanno, K. Murai, H. Kobatake, H. Fukuyama, T. Tsukada and M. Watanabe: ISIJ Int. 54 (2014) 2120-2124.

65) T. B. Massalski, H. Okamoto, P. R. Subramanian, L. Kacprzak: Binary Alloy Phase Diagrams, 2nd ed., vol. 2, (American Society for Metals, Metals Park, Ohio, 1990) p. 1772.

66) L.S. Darken: Trans. Metall. AIME 175 (1948) 184-201.

67) P.G. Sanders and M.J. Aziz: J. Appl. Phys. 86 (1999) 4258-4261.

68) L. Yang, M.T. Simnad and G. Derge: Trans. Metall. AIME 206 (1956) 1577-1580.

69) R. Hultgren, P. D. Desai, D. T. Hawkins, M. Gleiser and K. K. Kelley: Selected Values of the Thermodynamic Properties of Binary Alloys, (American Society for Metals, Metals Park, Ohio, 1973) pp. 871-883.

70) M. Petrescu: Z. Metallk. 61 (1970) 14-18.

71) H.E. Cline and T.R. Anthony: J. Appl. Phys. 43 (1972) 4391-4395.

72) T.R. Anthony and H.E. Cline: J. Appl. Phys. 43 (1972) 2473-2476.

73) X. Ma, T. Yoshikawa and K. Morita: Sci. Adv. Mater. 6 (2014) 1697-1701.

74) H. Higuchi, K. Kimura, A. Mizuno, M. Watanabe, Y. Katayama and K. Kuribayashi: Meas. Sci. Technol. 16 (2005) 381-385.

75) Y. Kita, M. Zeze and Z. Morita: Trans. ISIJ 22 (1982) 571-576.

76) F. D. Richardson: Physical Chemistry of Melts in Metallurgy, (Academic Press, London, 1974) p. 4. 